\author{
Lecturer Melinda Timea FÜLÖP, PhD \\ E-mail: melinda.fulop@econ.ubbcluj.ro \\ "Babeș-Bolyai" University \\ Associated Professor Attila SZORA TAMAS, PhD \\ E-mail: attaconsulting@yahoo.com \\ Associated Professor Oana Raluca IVAN, PhD \\ E-mail: raluca.ivan@uab.ro \\ "1 Decembrie 1918" University \\ Lecturer Alina Nicoleta SOLOVĂSTRU, PhD \\ E-mail: alina.solovastru@yahoo.com \\ "Dimitrie Cantemir Christian" University
}

\title{
REGRESSIVE MODEL REGARDING THE NECESSARY PROFIT MARGIN FORECAST FOR A NEW PROJECT IN THE CONSTRUCTIONS FIELD
}

\begin{abstract}
Assuming that any entrepreneur starts a new business to make a profit eventually, the authors feel it was necessary to analyze the profit margin that actually indicates the percentage of how profitable the activity of the company is. In order to analyze the evolution of the average profit margin and to forecast it for a new project in the constructions field, the authors applied a regression model based on the monthly statistical data obtained from the entity. Following the data collection, the authors analyzed to what extent the statistical processing leads to a more efficient management of specific operations to execute the project. The outcome of the regression shows a non-uniformity of the activities of the project, which has led to a large variation of the economic indicators, from one month to another or from year to year. As a result, the authors failed to estimate the average profit margin over the entire execution period, nonetheless obtained average estimates for each year separately.
\end{abstract}

Keywords: profit margin, regression, forecast.

\section{JEL Classification: M41}

\section{Introduction}

Starting from the premise that any entrepreneur starts a new business with the aim of making the business, sooner or later, a profitable one, it is necessary to analyze the profit margin because this indicates, as a percentage, how profitable the total activity of a business is. The purpose of any business is to make a profit that will ensure the premises of continuity and allow the entrepreneur to obtain a 
Melinda Timea Fülöp, Attila Szora Tamas, Oana Raluca Ivan, Alina Nicoleta Solovăstru

necessary income for existence (Scridon, 2008). Thus it can happen that during the course of daily activities it can sell more or less, have a large volume of transactions, but at the end of the period we find that the profit is small or absent.

It is also true that sometimes in the sales mix you can have margin products that are very profitable and volume products that are not necessarily profitable but have the advantage of attracting customers to higher profit products or generating turnover (Cordoș \&Fülöp,2014, Medeleanu et al., 2019). This must be an assumed decision and the entrepreneur must know what these products are and determine what his business strategy is (Măgdaș\&Fülöp, 2019; Anghelache et al., 2019).

In the literature, we undertook a series of examinations regarding the evolution of the average profit margin as well as the influences of the profit on different industries and fields of activity. Hodder (1984) and Hodder\&Dincer (1986), since the early 1980s, emphasize that the sales process has long-term risks and opportunities, and not only short-term returns, and therefore must be carefully evaluated. At the end of the 1980s and 1990s, there was a noticeable shift in investment motivation, from a financial orientation to a long-term strategic orientation (MacCormack et al. 1994, Bartmess 1994). This has been largely confirmed by the investment decisions of Japanese companies and European companies in the US market (Bolwijn\& Brinkman 1987).

Profit margins are a contemporary reflection of an entity's operational performance (Penman \& Zhang, 2006; Soliman, 2008; Zhou, 2016; Zhao et al., 2016a and 2016b; Lee, 2016). Over time, however, competition constrains prices, both at the level of the entire economy and within the factors of the industry, which determines the profit margins in a competitive equilibrium to approach part of the industry average (Subramanyam, 2014). Therefore, the quality of financial reporting with regards to the information that profit margins convey to investors can be generally limited to the period analyzed.

Fairfield and Yohn (2001) document that profit margin levels and turnover do not predict future profitability of net operating assets, while changes in profit margin and return on assets predict return on assets a year earlier, with changes in turnover of assets constituting a leading indicator of future profitability. They also state that changes in the turnover of assets can forecast changes in operating income, while changes in profit margin do not. Amir et al. (2011) provide evidence that the contemporary market reaction to the profit margin is stronger than that of the turnover or the assets.

Therefore, our model aims to study the evolution of the average profit margin for an executed project, in the constructions field and its application for a new project to be executed. The statistical data is monthly and refers to a project that was executed over a period of three years.

In a first phase we will identify and analyze the factors with a significant impact on the variation of the average profit margin. Some of these factors are specific to the main contractor and another part to the subcontractors. Based on the 
Regressive Model Regarding the Necessary Profit Margin Forecast for a New Project in the Constructions Field

statistical data which is made available to us, we analyzed the statistical and economic significance of their influence on the variation of the average profit margin, a relevant indicator for an entrepreneur. We consider that it is relevant to quantify these influences numerically in order to correct, in real time, any deviations from the profit indicators.

Finally, based on the statistical model, we will analyze its applicability to a new project to be executed. In this sense, a projection is made for the first year. This projection will help us analyze the monthly deviations of the average profit margin. We will analyse the extent the possible adjustment of the impact factors can lead to maintaining the execution of the project within the projected parameters.

In conclusion, we will examine to what extent the statistical processing of the data (the econometric model) can lead to a more efficient (dynamic) management of the specific operations for the execution of the project.In the following we will present the methodology, the econometric model, followed by underlining the economic and the obtained results.

\section{Research methodology}

\subsection{The regression models}

We propose to analyze the factors that have a significant impact on the variation of the profit margin. In a first phase we will consider that the dependent variable y (profit margin) depends only on a single independent variable (factor) $\mathrm{x}$. Regression is a much more flexible and powerful statistical tool than correlation.

In view of prior relevant literature reviewed, the researcher might identify a possible between two variables $\mathrm{y}$ and $\mathrm{x}$ and that. A first step in the verification of intuition is the graphical representation of the values of the variables (we choose statistical cloud). The graphical representation might allow us to formulate a hypothesis regarding the analytical form of the relationship between the two sizes.

Suppose the researcher senses that there is a relationship between the two variables $\mathrm{y}$ and $\mathrm{x}$ and that economic theory supports such a connection. A first step in the verification of intuition is the graphical representation of the values of the variables (statistical cloud is recommended). The graphical representation allows us to formulate a hypothesis regarding the analytical form of the relationship between the two sizes. Since we are in the simple linear case suppose that the functional expression of the connection is a straight line of the form:

$$
y_{i}=\alpha+\beta x_{i}+u_{i} .
$$

The index i shows the number of statistical observations, $\alpha$ and $\beta$ are the parameters of the model and $u_{i}$ the errors (residuals). The model gets closer to reality by introducing the error term which is random. The best known method for estimating the parameters $\alpha$ and $\beta$ is the method of least squares (OLS). Let $y_{i}$ be the real value of the observation for the statistical unit $i$, and $\hat{y}_{i}$ the estimated value 
Melinda Timea Fülöp, Attila Szora Tamas, Oana Raluca Ivan, Alina Nicoleta Solovăstru

(using the regression line). The estimated value of the error is calculated as the difference between the two sizes, as follows:

$$
\hat{u}_{i}=y_{i}-\hat{y}_{i}
$$

According to the OLS method, the estimated model parameters, $\hat{\alpha}$ and $\hat{\beta}$, are obtained by minimizing the sum of the squares of the estimated errors, according to the relationship below:

$$
\min _{\alpha, \beta} \sum_{i=1}^{N} \hat{u}_{i}^{2}
$$

Where: $\mathrm{N}$ is the number of statistical observations. The OLS estimation method ensures the uniqueness of the estimates for the model parameters. The positive / negative value for $\hat{\beta}$, shows us whether the two variables y and $\mathrm{x}$ evolve in the same direction or in different directions. Great attention must be paid to the interpretation of the estimation $\hat{\alpha}$ as well as the predictions of the variable $y$ for values of the variable $\mathrm{x}$ that do not belong to the domain recorded for the statistical observations in question. In order to clarify and better understand the model, we will insist on some specific notions of econometric modelling.

Previously we defined and commented on what we call a simple linear model;

$$
y_{i}=\alpha+\beta x_{i}+u_{i} \quad \mathrm{i}=\overline{1, N} .
$$

This equation is bivariate simple regression model. The change of the dependent variable is explained by the variation of the independent variable. Economic theory and beyond, most often suggest the idea of several factors of influence. In generalized form, the econometric model with $\mathrm{k}$ independent variables looks like this:

$$
y_{i}=\beta_{1}+\beta_{2} x_{2 i}+\beta_{3} x_{3 i}+\cdots+\beta_{k} x_{k i}+u_{i} \mathrm{i}=\overline{1, N}
$$

The variables $x_{2 i}, x_{3 i}, \cdots, \mathrm{x}_{\mathrm{ki}}$ form k-1 explanatory variables with impact on the dependent variable $y$ and the parameters $\beta_{1}, \beta_{2}, \cdots, \beta_{k}$ quantify the effect of these variables. Each coefficient is known as the partial regression coefficient, interpreted as the partial effect of an independent variable on the dependent variable, while constantly maintaining all other variables. For example, $\hat{\beta}_{2}$, measures the effect of the variable $x_{2}$ on the variable $y$ after removing the effect of the other variables. More concretely, each coefficient measures the change in the average of the dependent variable for a one-unit modification of an independent variable, keeping the other variables constant at the mean values.

\section{Variables and data collection}

The data source is the accounting documents that reflect the execution of the project for the period 2013-2015. Although the accounting data is much more detailed, we will refer only to information regarding to the study in question.

The values of the variables are monthly. The constructed database, based on the accounting statements, is the source of information regarding the execution of the project during the period considered. 
Regressive Model Regarding the Necessary Profit Margin Forecast for a New Project in the Constructions Field

\section{Analysis and presentation of results}

In this regard we will analyze the most relevant results obtained from the statistical processing. The highlighted statistical links will be the subject of this section. Based on the obtained information, we will emphasize their role in substantiating the decisions regarding the management of future projects, in the applicability part of the model.

The 8 variables (presented above): Profit margin, Total costs, Direct costs, indirect cost, Revenue, Total hours worked, Total hours subcontractors and Total machine hours will be the subject of analysis of relevant statistical links. Table 1 shows the level of correlation between the variables considered.

Table 1.Level of correlation between variables

\begin{tabular}{|l|l|l|l|l|l|l|l|}
\hline Element & $\begin{array}{l}\text { Profit } \\
\text { margin }\end{array}$ & $\begin{array}{l}\text { Total } \\
\text { costs }\end{array}$ & $\begin{array}{l}\text { Direct } \\
\text { costs }\end{array}$ & $\begin{array}{l}\text { Indirect } \\
\text { costs }\end{array}$ & Income & $\begin{array}{l}\text { Total hours } \\
\text { subcontractors }\end{array}$ & $\begin{array}{c}\text { Total } \\
\text { machine } \\
\text { hours }\end{array}$ \\
\hline Profit margin & 1.0000 & & & & & & \\
\hline Total costs & 0.9941 & 1.0000 & & & & & \\
\hline Direct costs & 0.9702 & 0.9836 & 1.0000 & & & & \\
\hline Indirect costs & 0.9779 & 0.9740 & 0.9171 & 1.0000 & & & \\
\hline Income & 0.9956 & 0.9999 & 0.9825 & 0.9752 & 1.0000 & & \\
\hline $\begin{array}{l}\text { Total hours } \\
\text { subcontractors }\end{array}$ & 0.0647 & 0.1396 & 0.1774 & 0.0856 & 0.1297 & 1.0000 & 1.0000 \\
\hline $\begin{array}{l}\text { Total machine } \\
\text { hours }\end{array}$ & 0.1363 & 0.2178 & 0.2723 & 0.1392 & 0.2071 & 0.7950 & \\
\hline
\end{tabular}

The correlation table above shows a high level of correlation between the dependent variable Profit margin and the other variables included in the table, with the exception of the last two, Total hours subcontractors and Total machine hours.

We will analyze the impact of each independent variable on the variation of the average profit margin, for the entire period considered, and where appropriate for each particular year.

As shown in Table 1, there is a strong correlation between the profit margin and the total costs (the correlation coefficient is 0.9941). The graph in Figure 1 suggests a linear link between the two variables. The arrangement of the statistical cloud suggests a direct linear connection (increasing the independent variable has the effect of increasing the dependent variable). 
Melinda Timea Fülöp, Attila Szora Tamas, Oana Raluca Ivan, Alina Nicoleta Solovăstru

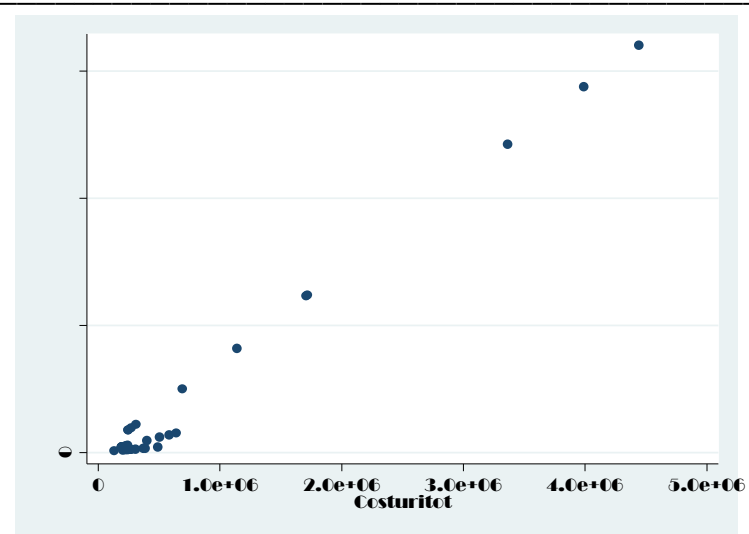

Figure 1.Cloud between Profit margin and Total costs

The independent variable Total costs is statistically significant, since the statistic $\mathrm{F}=14557.88$ and the $\mathrm{p}$-value is 0.000 . At the same time, the change in profit margin is explained by $98.83 \%$ by the total costs. The impact of total costs is statistically significant, since the corresponding p-value is 0.000 . For an increase of 100 Lei of the total costs, the profit increases on average with 15.19 Lei, this is also significant from an economic point of view. The positive sign of the coefficient of the variable Total costs (.1519751) shows us that between the profit margin and the total costs there is a direct link, as expected. In Table 15 there are other statistical sizes, which we do not insist on, which show us that the econometric model is statistically valid. The direct link between the two variables is explained by the fact that the statistical data reflect the activities related to a construction project from the point of view of the General Contractor, which subcontracts the execution of the work at a lower price than what it receives from the final client. The model highlights the client-contractor-subcontractor relationship.

A variable with a significant impact on the variation of the average profit margin is the variable direct costs, which quantifies the impact of direct costs. The correlation level between the two variables is 0.9702 , as shown in Table 1 .

Table 2. OLS of the Profit margin with the Total costs

\begin{tabular}{|c|c|c|c|c|c|c|}
\hline & \multicolumn{2}{|c|}{$\begin{array}{l}\text { Linear regression } \\
\mathrm{F}(1,31)=14557.88 \\
\text { R-squared }=0.9883\end{array}$} & & \multicolumn{3}{|c|}{$\begin{array}{l}\text { Number of obs }=33 \\
\text { Prob }>F=0.0000 \\
\text { Root } M S E=18431\end{array}$} \\
\hline & Coef. & $\begin{array}{l}\text { Robust } \\
\text { Std. Err. }\end{array}$ & $\mathrm{t}$ & $\mathrm{P}>|\mathrm{t}|$ & [95\% Conf & nterval] \\
\hline Profit margin & .1519751 & .0012596 & 120.66 & 0.000 & .1494062 & .154544 \\
\hline Total costs & -28414.29 & 3757.069 & -7.56 & 0.000 & -36076.88 & -20751.7 \\
\hline
\end{tabular}

The statistical cloud in Figure 2 suggests a relevant and direct statistical connection. Table 3 shows that the (suggested) anticipated hypothesis is true. The 
Regressive Model Regarding the Necessary Profit Margin Forecast for a New Project in the Constructions Field

impact of the direct costs, on the profit margin, is greater than the impact of the total costs. For a 100 lei increase in total expenses, the profit margin increases by 26 lei. The impact of the direct costs is statistically significant ( $\mathrm{p}$-value $=0.000$ ) and the increase of the profit corresponding to the increase of the direct costs is economically relevant (26 Lei profit at an increase with 100 Lei of the direct costs). The change in the profit margin is explained by $94.13 \%$ by the variation of the direct costs.

\section{Table 3. OLS of the Profit margin with the Direct costs}

\begin{tabular}{|c|c|c|c|c|c|c|}
\hline & \multicolumn{3}{|c|}{$\begin{array}{l}\text { Linear regression } \\
\mathrm{F}(1,31)=242.56 \\
\text { R-squared }=0.9413\end{array}$} & \multicolumn{3}{|c|}{$\begin{array}{l}\text { Number of obs }=33 \\
\text { Prob }>F=0.0000 \\
\text { Root } M S E=41345\end{array}$} \\
\hline & Coef. & $\begin{array}{l}\text { Robust } \\
\text { Std. Err. }\end{array}$ & $\mathrm{t}$ & $\mathrm{P}>|\mathrm{t}|$ & [95\% Conf & [nterval] \\
\hline Profit margin & .2610262 & .0167599 & 15.57 & 0.000 & .2268442 & .2952081 \\
\hline Direct costs & -14397.19 & 7443.513 & -1.93 & 0.062 & -29578.34 & 783.95 \\
\hline
\end{tabular}

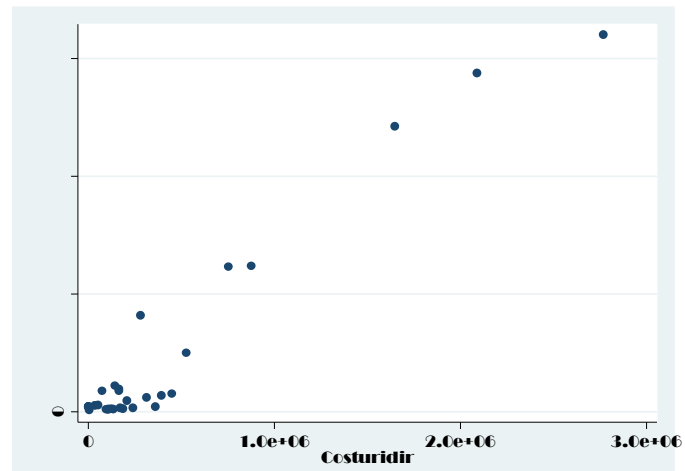

Figure 2.Cloud between Profit margin and Direct costs

Indirect costs are another independent variable with a strong impact on the variation of the average profit margin. The results sow a linear model between the to variables as we can see the results in table 4 . The change in the profit margin is explained by $95.62 \%$ by the variation of the indirect costs. The coefficient of the independent variable is about 0.33 , which means that at an increase of 100 lei of indirect expenses, the profit will increase by 33 lei. The impact of the variable indirect costs is statistically significant (p-value $=0.000)$ as well as economical considering the increase in profit in relation to this factor. All three factor variables studied have a relevant impact on the variation of the average profit margin. 
Melinda Timea Fülöp, Attila Szora Tamas, Oana Raluca Ivan, Alina Nicoleta Solovăstru

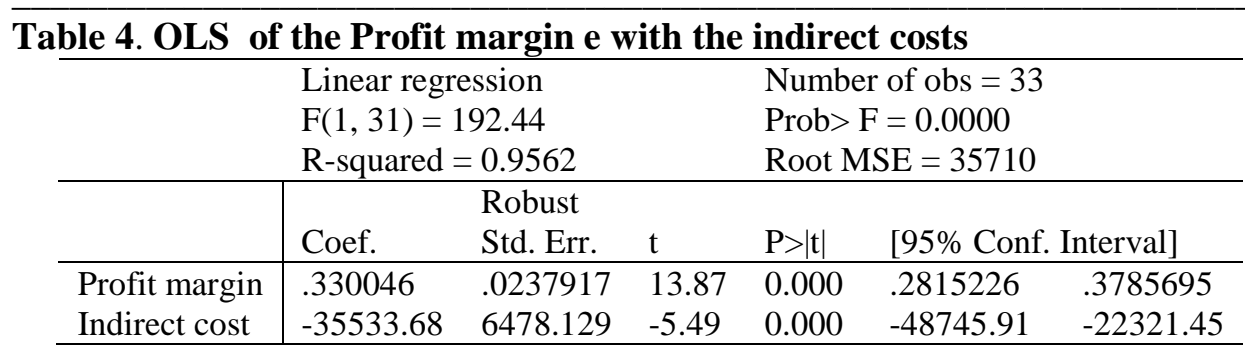

Income is the variable (indicator) that most closely correlates with the independent variable (Profit margin). According to the correlation table, there is a correlation of $99.56 \%$ between the two variables. The statistical cloud in Figure 3 allows us to support the hypothesis that there is a linear connection between them. The statistical elements in Table 5 show that the hypothesis issued is true. The change in the profit margin is explained by $99.12 \%$ by the variation of the independent variable Income. The coefficient of the variable Income shows us that at an increase of 100 Lei of income, the profit margin will increase on average by about 13 Lei. The impact of the income on the profit modification is statistically significant, because the corresponding p-value is 0.000 . The same can be said about the economic significance of the impact. Income growth is a source of profit, in this case 13 Lei profit to 100 Lei income. Of the variables studied, the variable income is most strongly correlated with the profit margin.

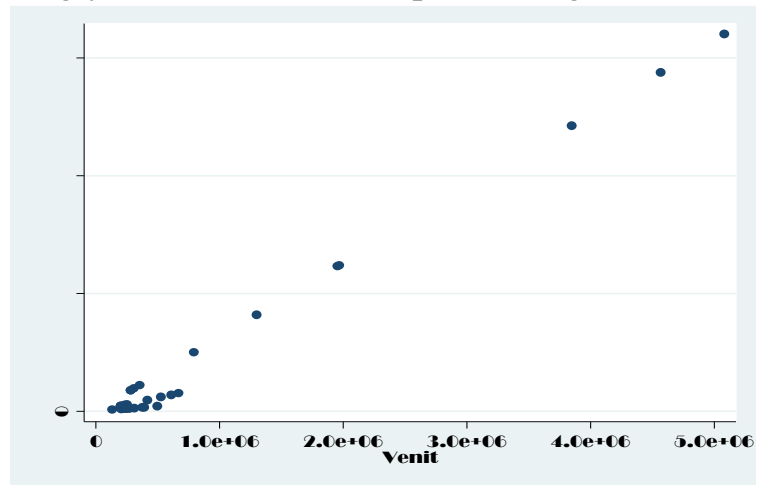

Figure 3.Cloud between Profit margin and Revenue

Another important variable in terms of influence on profit margin is Total hours worked. We expect that the number of hours worked, at the level of the entrepreneur, will influence the profit margin. We have the statistical cloud between the two variables, during the 3 years. The model presented in Table 6 does not suggest any possible link between them.

We will analyze a possible connection, between the two variables, at the level of each year. Table 6 shows that at the level of 2013 we cannot conclude a possible influence of the total hours worked on the profit margin. 
Regressive Model Regarding the Necessary Profit Margin Forecast for a New Project in the Constructions Field

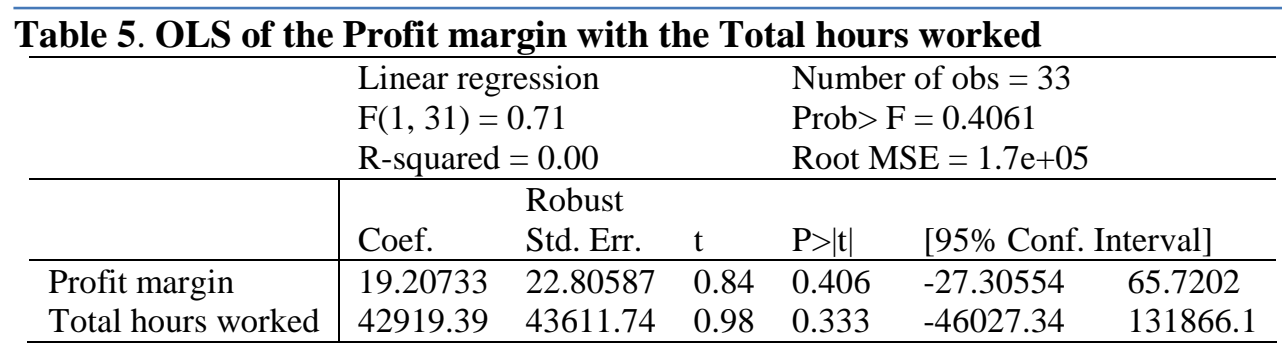

Table 6. OLS of the Profit margin with the Total hours worked (2013)

\begin{tabular}{|c|c|c|c|c|c|c|}
\hline & \multicolumn{3}{|c|}{$\begin{array}{l}\text { Linear regression } \\
\mathrm{F}(1,8)=2.60 \\
\text { R-squared }=0.1349\end{array}$} & \multicolumn{3}{|c|}{$\begin{array}{l}\text { Number of obs }=10 \\
\text { Prob }>F=0.1454 \\
\text { Root } M S E=8507.6\end{array}$} \\
\hline & Coef. & $\begin{array}{l}\text { Robust } \\
\text { Std. Err. }\end{array}$ & $\mathrm{t}$ & $P>|t|$ & [95\% Conf. & [nterval] \\
\hline Profit margin & 6.275817 & 3.891055 & 1.61 & 0.145 & -2.696971 & 15.2486 \\
\hline Total hours worked & 2104.501 & 7222.317 & 0.29 & 0.778 & -14550.19 & 18759.19 \\
\hline
\end{tabular}

However, we can see that the p-value for the factor variable decreases with respect to the p-value corresponding to the same factor in Table 5.

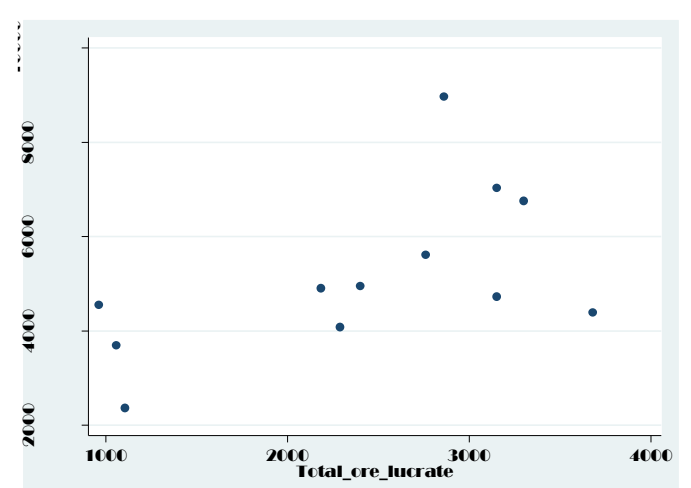

Figure 4.Cloud between Profit margin and Total hours worked (2014)

Figure 4 corresponding to 2014, show us that there is a linear connection between the two variables. More specifically, in 2014 the impact of the number of hours worked on the average profit margin is statistically significant ( $\mathrm{p}$-value = $0.047<0.05$ ). If the number of hours worked increases by 100 then the profit increases by 105 Lei.

Table 7 show a much more intense connection, both from a statistical point of view and from an economic point of view. The p-value for the factor variable is 0.017 which means that the impact is relevant. We can conclude that an increase of 100 hours worked, the profit margin increases on average by 215 Lei. Compared 
Melinda Timea Fülöp, Attila Szora Tamas, Oana Raluca Ivan, Alina Nicoleta Solovăstru

to the previous year, in 2015 there is a high increase in the average profit margin. The data available show us a big difference between the profits obtained in the two consecutive years, caused by a much more intense activity.

Table 7.OLS of the Profit margin with the Total hours worked (2015)

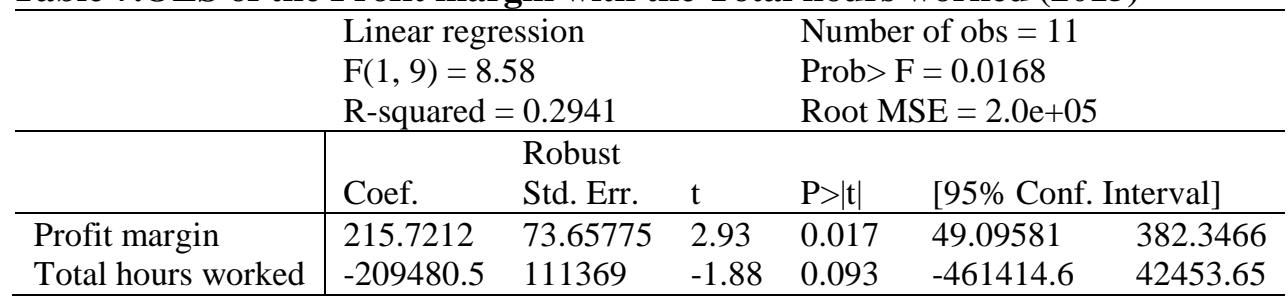

From similar examinations, we conclude that the hourly rate and the wage expenses do not have a significant impact on the average variation of the profit margin.

The main contractor carries out his activity, most of the time, using subcontractors according to the specificity of the works to be executed. We considered two variables: Total hours subcontractors and Total machine hours, presented in the data description part. We propose to analyse whether these variables have a significant impact on the variation in the profit margin. As we have mentioned, the activity of the company is not continuous during the period considered (it is performed in jumps). As a result, we will analyse the impact on each year, as well as on the total period.

In Figure 5we observed that during the whole period we cannot determine a significant impact of the total of the subcontracted hours on the average variation of the profit margin. The statistical cloud suggests that the data are divided into at least two groups. For this reason we will try to address the impact issue for each year separately. The results shows that the variable Total hours subcontractors does not influence the variation of the Profit margin variable $(p$-value $=0.556)$.

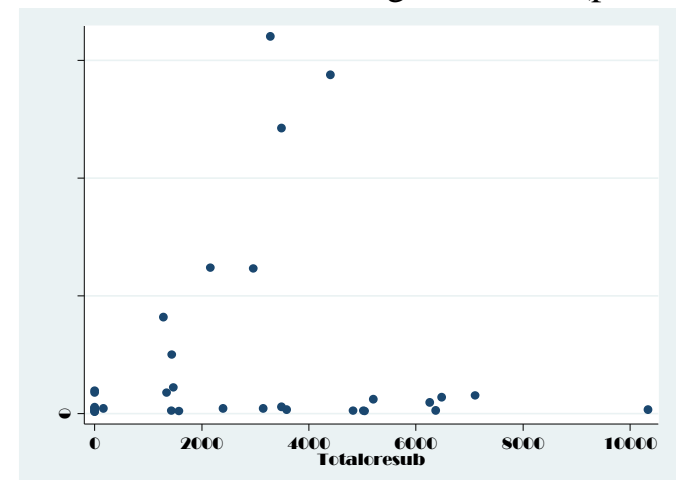

Figure 5.Cloud between Profit margin and Total hours subcontractors 
Regressive Model Regarding the Necessary Profit Margin Forecast for a New Project in the Constructions Field

In Table 8 we analyzed the total impact of the subcontracted hours on the variation of the average profit margin for 2013. The statistical cloud makes us believe that there is a direct linear connection between the two variables.

Table 8. OLS of the Profit margin with the Total hours subcontractors (2013)

\begin{tabular}{|c|c|c|c|c|c|c|}
\hline & \multicolumn{3}{|c|}{$\begin{array}{l}\text { Linear regression } \\
F(1,8)=42.70 \\
\text { R-squared }=0.8087\end{array}$} & \multicolumn{3}{|c|}{$\begin{array}{l}\text { Number of obs }=10 \\
\text { Prob }>F=0.0002 \\
\text { Root MSE }=4001.1\end{array}$} \\
\hline & Coef. & $\begin{array}{l}\text { Robust } \\
\text { Std. Err. }\end{array}$ & $\mathrm{t}$ & $\mathrm{P}>|\mathrm{t}|$ & [95\% Con & nterval] \\
\hline Profit margin & 2.602169 & .3982142 & 6.53 & 0.000 & 1.683886 & 3.520453 \\
\hline $\begin{array}{l}\text { Total hours } \\
\text { subcontractors }\end{array}$ & 7992.376 & 1251.303 & 6.39 & 0.000 & 5106.866 & 10877.89 \\
\hline
\end{tabular}

According to Table 11, in 2013 the subcontracted hours have a positive impact on the profit margin. For an increase with one hour of subcontracted hours, the profit margin increases by an average of 2.6 lei. The impact is statistically significant ( $p$-value $=0.000$ ). Nor is the increase in profit relative to the increase in subcontracted hours. At 100 hours subcontracted, the profit increases by an average of 260 lei, which shows an increase in the intensity of activity in 2013. In 2014, the situation is different from the previous year.

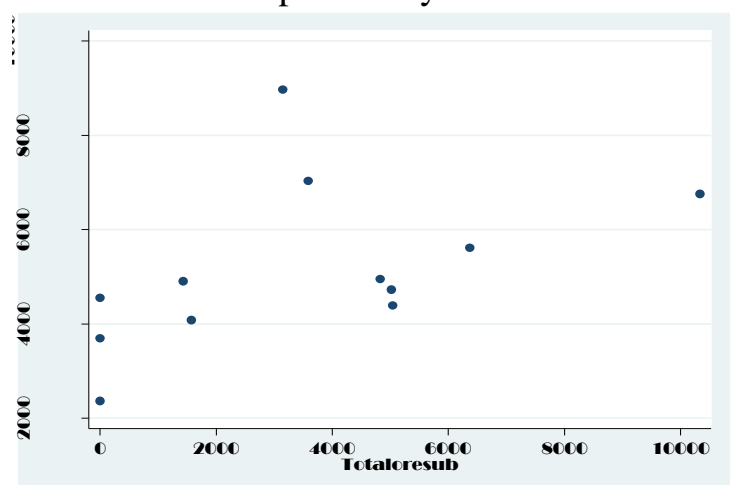

Figure 6.Cloud between Profit margin and Total hours subcontractors (2014)

Figure 6 show that at an increase of 100 of the subcontracted hours the profit increases by approximately 27 Lei. This year the profit growth is much slower compared to the previous year. An analysis of the activity is required in order to detect the causes of the slowing of the profit margin. Figure 6 is relevant in this regard. It can be observed that for the same values of the subcontracted hours, the profit is much diminished compared to 2013.

The link between the two variables for 2015 is shown in Table 9. We observe a direct linear connection, with a significant economic impact of the subcontracted hours on the average variation of the profit margin. 
Melinda Timea Fülöp, Attila Szora Tamas, Oana Raluca Ivan, Alina Nicoleta Solovăstru

For an increase with one hour of subcontracted hours, the profit margin increases by an average of 142.96 Lei. According to the results, we can see the high profit registered in the months of 2015. The same explanation, an intensification of the activities within the project.

Table 9.OLS of the Profit margin with the Total hours subcontractors (2015)

\begin{tabular}{|c|c|c|c|c|c|c|}
\hline & \multicolumn{3}{|c|}{$\begin{array}{l}\text { Linear regression } \\
\mathrm{F}(1,9)=41.36 \\
\text { R-squared }=0.7877\end{array}$} & \multicolumn{3}{|c|}{$\begin{array}{l}\text { Number of obs }=11 \\
\text { Prob }>F=0.0001 \\
\text { Root } M S E=1.1 \mathrm{e}+05\end{array}$} \\
\hline & Coef. & $\begin{array}{l}\text { Robust } \\
\text { Std. Err. }\end{array}$ & $\mathrm{t}$ & $\mathrm{P}>|\mathrm{t}|$ & {$[95 \%$ Con } & [nterval] \\
\hline Profit margin & 142.9674 & 22.2299 & 6.43 & 0.000 & 92.67985 & 193.2549 \\
\hline $\begin{array}{l}\text { Total hours } \\
\text { subcontractors }\end{array}$ & -45996.56 & 47963.3 & -0.96 & 0.363 & -154497.1 & 62503.96 \\
\hline
\end{tabular}

Another factor with a significant influence on the variation of the profit margin is the total hours allocated for the rental of the machines (Total machine hours). The impact of this variable is similar to that of the Total hours subcontractors variable.

For the entire three-year period we cannot speak of a statistically significant impact. Figure 7 and Table 10 are relevant from this point of view. The statistical cloud suggests that the data are arranged from two different directions at least. One direction shows us that the profit margin shows a higher growth and the other one shows a slower growth. Table 14 summarizes the statistical model regarding the impact of the Total machine hours variable on Profit margin. Over the three years we cannot validate about such an impact, as the total value for Total machine hours is $0.357>0.05$. As a result, we will analyse the model for each year, to study a possible annual impact.

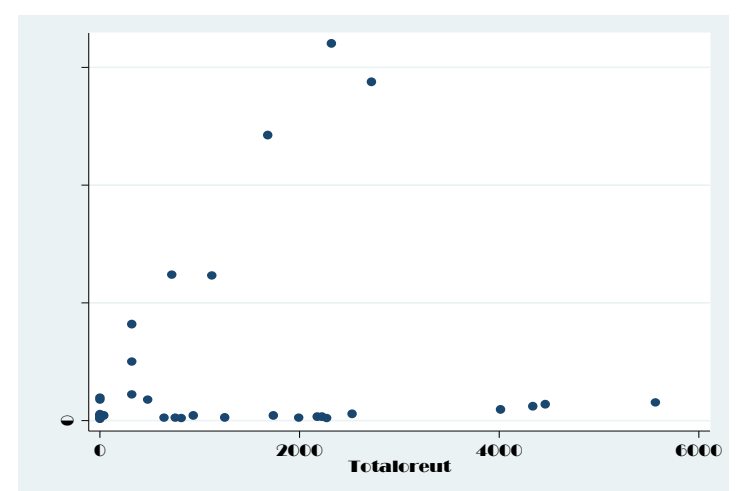

Figure 7.Cloud between Profit margin and Total machine hours 
Regressive Model Regarding the Necessary Profit Margin Forecast for a New Project in the Constructions Field

\begin{tabular}{|c|c|c|c|c|c|c|}
\hline & $\begin{array}{l}\text { Linear reg } \\
\mathrm{F}(1,31)= \\
\mathrm{R} \text {-squared }\end{array}$ & $\begin{array}{l}\text { ession } \\
.88 \\
=0.0186 \\
\end{array}$ & & $\begin{array}{l}\text { Numb } \\
\text { Prob> } \\
\text { Root } 1\end{array}$ & $\begin{array}{l}\text { of obs }=33 \\
=0.3566 \\
E=1.7 \mathrm{e}+05\end{array}$ & \\
\hline & Coef. & $\begin{array}{l}\text { Robust } \\
\text { Std. Err. }\end{array}$ & $\mathrm{t}$ & $P>|t|$ & [95\% Conf. & [nterval] \\
\hline $\begin{array}{l}\text { Profit margin } \\
\text { Total machine hours }\end{array}$ & $\begin{array}{l}15.18782 \\
64916.34\end{array}$ & $\begin{array}{l}16.22919 \\
2201726\end{array}$ & $\begin{array}{l}0.94 \\
2.95\end{array}$ & $\begin{array}{l}0.357 \\
0.006\end{array}$ & $\begin{array}{l}-17.91183 \\
2001185\end{array}$ & $\begin{array}{l}48.28748 \\
1098208\end{array}$ \\
\hline
\end{tabular}

The hours allocated to the rented machines significantly influence the variation of the profit for each year. Figure 8 and Table 11 show the existence of a direct linear connection between the two variables, for 2013. The regression model summarized in Table 11 shows that at an increase of 100 of the hours allocated to the rented machines the profit increases on average by 360 Lei. The impact of the Total machine hours variable is statistically significant, because the $\mathrm{p}$-value = 0.000 (corresponding to the factor variable).

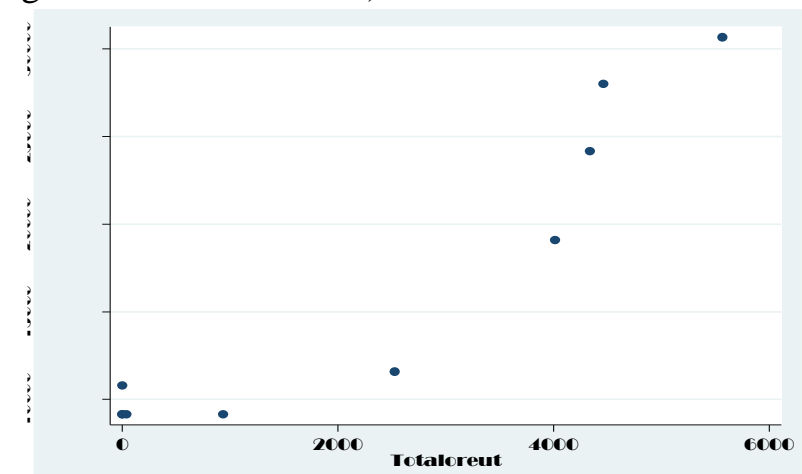

Figure 8.Cloud between Profit margin and Total machine hours(2013)

Table 11. OLS of the Profit margin with the Total machine hours (2013)

\begin{tabular}{lllllll}
\hline & \multicolumn{2}{l}{ Linear regression } & \multicolumn{3}{l}{ Number of obs $=10$} \\
& \multicolumn{1}{l}{$\mathrm{F}(1,8)=90.17$} & \multicolumn{3}{l}{ Prob $>\mathrm{F}=0.0000$} \\
& $\mathrm{R}$-squared $=0.8802$ & & \multicolumn{2}{l}{ Root MSE $=3165.5$} \\
& \multicolumn{3}{c}{ Robust } \\
& Coef. & Std. Err. & $\mathrm{t}$ & $\mathrm{P}>|\mathrm{t}|$ & [95\% Conf. Interval] \\
\hline Profit margin & 3.609716 & .3801427 & 9.50 & 0.000 & 2.733105 & 4.486326 \\
Total machine hours & 8181.055 & 998.5236 & 8.19 & 0.000 & 5878.455 & 10483.65 \\
\hline
\end{tabular}

For 2014 (Figure 9), the impact is less significant from an economic point of view. For an increase by 100 of the total hours of rented machines the profit increases on average by 120 Lei (quite small). 
Melinda Timea Fülöp, Attila Szora Tamas, Oana Raluca Ivan, Alina Nicoleta Solovăstru

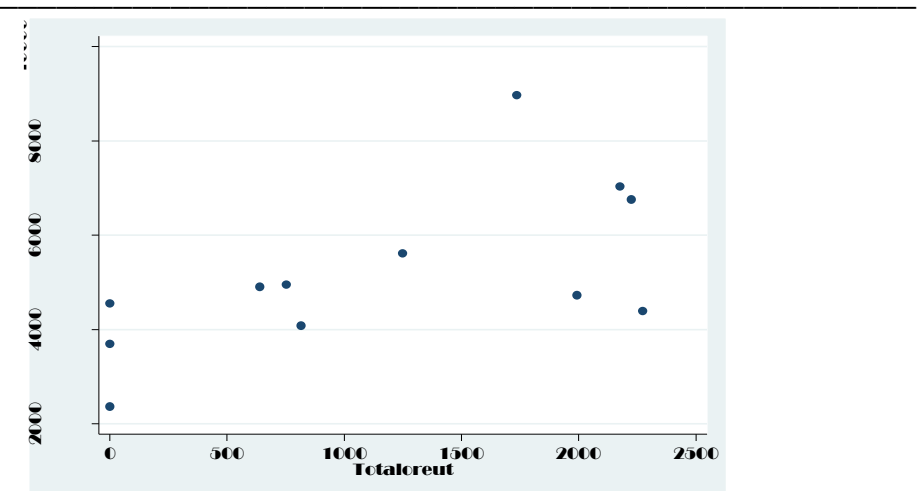

Figure 9. Cloud between Profit margin and Total machine hours(2014)

The impact of the Total machine hours variable on the Profit margin variable is statistically significant ( $\mathrm{p}$-value $=0.027<0.05)$.

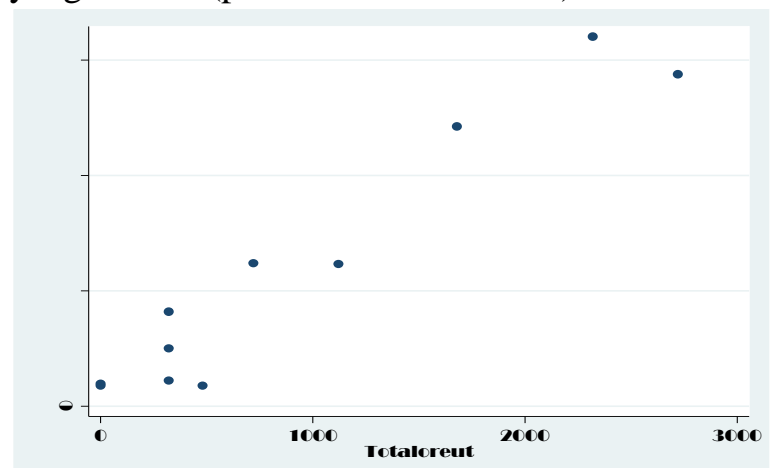

Figure 10.Cloud between Profit margin and Total machine hours(2015)

For 2015, the result of the model is summarized in Figure 10 and Table 12. The statistical cloud, presented above, suggests a linear model between the variables. The impact of the Total machine hours independent variable on the Profit margin dependent variable is statistically significant, since the $\mathrm{p}$-value $=$ 0.000 . The coefficient of the independent variable is 233.6991 , which means that for an increase with one hour of total machine hours, the profit margin will increase on average by about 234 lei (very high). We must note the profitability of the company in relation to the use of the machines rented in 2015. As a remark, we can emphasize the significant increase of the profit of the company in 2015 in relation to the number of hours in which the machines were rented. 
Regressive Model Regarding the Necessary Profit Margin Forecast for a New Project in the Constructions Field

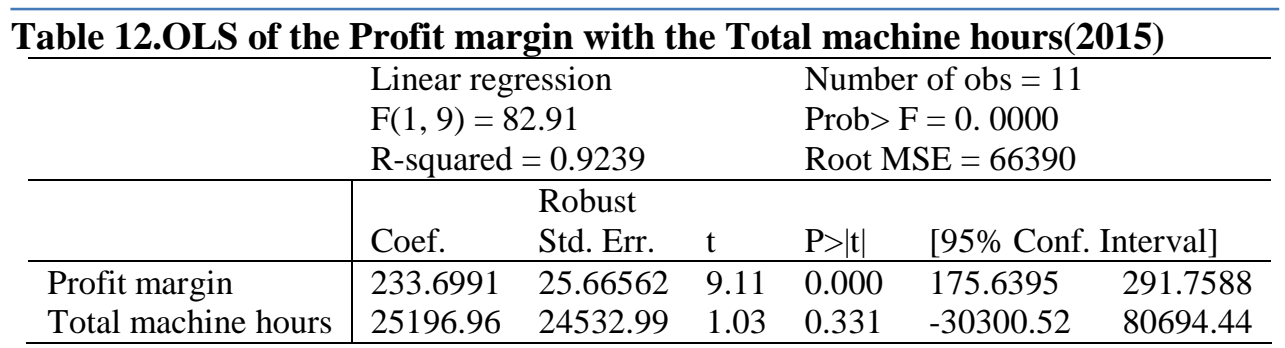

From Table 12, we observe a high level of correlation between the possible impact factors, which does not allow a concurrent estimation of their impact. In conclusion, we have only linear econometric models with a single impact factor. This does not affect the quality of the study, because the variables Income, Indirect costs, Direct costs and Total costs explain each one in a proportion of over $90 \%$ of the variation in profit margin. The introduction of another variable in the study would not significantly change the profit margin variation.

\section{Applicability of the model}

In the previous sections we presented and analysed a linear econometric model, implemented using the data resulting from the execution of a construction project over a period of three years. It is natural to ask whether such a model can be applied for a project to be executed. We start from the hypothesis that the executor knows the project very well, both from an organizational point of view and the potential resources available to them. Our goal is to ensure a dynamic management of the project, in order to substantiate the decisions with the aim of keeping its ratios under control.

We will present, in the following, the phases necessary for the implementation of an econometric model for a construction project to be executed.

In the first phase, the executor must make a monthly projection of the indicators for the first year. This implies having experience from an organizational point of view, a thorough knowledge of the project-specific indicators (ratios) and a more accurate sizing of the resources available to it, and of the external resources to which it can appeal. The projection should include all indicators relevant to the project as well as their ranges of variation for each month, which should be in line with its value dimension and profitability.

In the second phase, a value is chosen for each indicator, from the interval specified for the first month, resulting in a set of values(data) specific to the execution of the first month of the first year. This process will be repeated for each month of that year, obtaining twelve sets of data. It is recommended that the data sets are in line with the profitability of the project, but also with the size of the resources of the executor. 
Melinda Timea Fülöp, Attila Szora Tamas, Oana Raluca Ivan, Alina Nicoleta Solovăstru

In the third phase, a graphical presentation of the dependent variable is made (in our case it is the margin of loss) in relation to each potential influence factor. The shape of the graph allows us to make a hypothesis about the form of the link between the factor and the dependent variable. Using a statistical processor, we obtain the first estimates for the coefficients of the factors introduced in the model.

In the fourth phase, we properly analyze and interpret the coefficients of the factor variables, resulting in the previous phase, both statistically and economically. If the results do not satisfy us, we will resume the procedure from the second phase, with possible resizing of the intervals of variation of the economic indicators that must be in accordance with the reality of the project.

If the results of the model satisfy us, statistically and economically, we can say that the executor has a possible impact of the factors on the monthly profitability of the first year project. Such a statistical methodology can be easily adapted for projects in other areas as well. In this case, the phases are the same, provided we analyse the linearity/non-linearity of the possible links.

\section{Conclusions}

Some conclusions and recommendations are needed in order to improve the management of a project in execution. The econometric model presented in the previous sections was implemented based on the data resulting from the execution of a project.

From the tables of data, from the graphical representations and from the results of the regression, we have found a non-uniformity of the activities of the project, which has led to a great variation of the economic indicators, from one month to another or from year to year. As a result of this we could not estimate the average profit margin over the entire period of execution, yet obtaining average estimates for each particular year. In this case, the impact of the following variables is included: Total machine hours, Total hours subcontractors and Total hours worked. Both from Table 1 (correlation) and from the presented econometric models, it turns out that the profit margin varies most when changing the following sizes: Income, Indirect costs, Direct costs and Total costs. It was expected that these variables would have the greatest impact on the average variation in the profit margin. Due to the non-uniformity of the monthly/annual execution of the project activities, the average profit margin can vary significantly from year to year.

The econometric model allows us to analyze the deviations (positive or negative) registered by the monthly profit margin obtained from the estimated average. It is important to find the explanations for these deviations in order to substantiate the decisions for a future project.

The model allows us to increase / decrease some impact factors (within the limits allowed by the performer) to observe how the profit margin changes. This comes to the support of the executor, in order to establish the values of the impact factors that lead to the most advantageous profit margin. 
Regressive Model Regarding the Necessary Profit Margin Forecast for a New Project in the Constructions Field

The econometric model can include several impact factors simultaneously. We observe a high level of correlation between the possible impact factors, which does not allow a concomitant estimation of their impact. In conclusion, we only have a linear econometric model with a single impact factor.

\section{REFERENCES}

[1]Amir, E., Kama, I. and Livnat, J. (2011), Conditional versus Unconditional Persistence of RNOA Components: Implications for Valuation; Review of Accounting Studies, 16(2): 302-327;

[2] Anghelache, C., Anghel, M.-G., Căpușneanu, S., Topor,D.I. (2019), Econometric Model Used for GDP Correlation Analysis and Economic Aggregates;Economic Computation and Economic Cybernetics Studies and Research; ASE Publishing; 53(1), 183-197;

[3] Bartmess, A. (1994), The Plant Location Puzzle.Harvard Business Review, March-April, 20- 37;

[4] Bolwijn, P. and Brinkman, S. (1987), Japanese Manufacturing: Strategy and Practice. Long Range Planning, 20, 25- 43;

[5] Cordoș, G. S.\& Fülöp, M. T. (2014),A Framework for Understanding and Researching Audit Changes: KezAudit Matters.AMIS 2014, 935;

[6] Fairfield P.M. and Yohn, T.L. (2001), Using Asset Turnover and Profit Margin to Forecast Changes in Profitability; Review of Accounting Studies, 6(4),371-385;

[7] Hodder, J. E.(1984), Financial Market Approaches to Facility Location under Uncertainty. Operations Research, 32, 1374- 1380;

[8] Hodder, J.E. and Dincer,M.C. (1986), A Multifactor Model for International Plant Location And ${ }^{\circledR}$ Nancing under Uncertainty. Computers and Operations Research, 13, 601- 609;

[9] Lee, D. H. (2016), Cost-benefit Analysis, LCOE and Evaluation of Financial Feasibility of Full Commercialization of Biohydrogen. International Journal of Hydrogen Energy, 41, 4347-4357;

[10] MacCormack,A.,NewmanIII,L.,Rosenfield,D. (1994), The New Dynamics of Global Manufacturing Site Location. Sloan Management Review, Summer, 6979 ;

[11] Măgdaș, N. \&Fülöp, M. T. (2019),Theoretical Approach between the Soft and Hard Law in the Context of Corporate Governance. Audit Financiar, 17(1), 134-141;

[12] Medeleanu F., Racuciu C., Nen M., Liepe Z., Antonie N.F.(2019)Fair elottery System Proposal Based on Anonymous Signatures; Applied economics, 51(27), 2921-2933; 
Melinda Timea Fülöp, Attila Szora Tamas, Oana Raluca Ivan, Alina Nicoleta Solovăstru

[13] Penman, S.H. and Zhang, X. (2006), Modeling Sustainable Earnings and P/E Ratios with Financial Statement Analysis, available at:

http://papers.ssrn.com/so13/paperscfm?abstract_id=318967,1ast accessed on 12.11.2019;

[14] Scridon, M. A. (2008), Understanding Customers-profiling and Segmentation. Management \& Marketing-Craiova, (1), 175-184;

[15] Soliman, M.T. (2008), The Use of DuPont Analysis by Market Participants, The Accounting Review, Vol. 83 No. 3, pp. 823-853;

[17] Subramanyam, K.R. (2014), Financial Statement Analysis, 14th ed., McGraw Hill, New York,NY, ISBN-13: 978-0078110962;

[18] Zhao, X. G., Jiang, G. W., Li, A., Li, Y., (2016b),Technology, Cost, a Performance of Waste-to-energy Incineration Industry in China. Renewable \& Sustainable Energy Reviews, 55, 115-130;

[19] Zhao, X. G., Jiang, G. W., Li, A., Wang, L.,(2016a), Economic Analysis of Waste-to-Energy Industry in China. Waste Management, 48, 604-618;

[20] Zhou, B. (2016), Lean Principles, Practices, and Impacts: A Study on Small and Medium-Sized Enterprises (SMEs). Annals of Operations Research, Advance online publication. 241 (1-2), 457-474. 